\title{
The translational expression of $A B C A 2$ and $A B C A 3$ is a strong prognostic biomarker for multidrug resistance in pediatric acute lymphoblastic leukemia
}

\author{
This article was published in the following Dove Press journal: \\ OncoTargets and Therapy \\ 10 July 2017 \\ Number of times this article has been viewed
}

\author{
Narges Aberuyi' \\ Soheila Rahgozar' \\ Zohreh Khosravi Dehaghi' \\ Alireza Moafi ${ }^{2}$ \\ Andrea Masotti ${ }^{3, *}$ \\ Alessandro Paolini $i^{3, *}$ \\ 'Department of Biology, Faculty \\ of Science, University of Isfahan, \\ ${ }^{2}$ Department of Pediatric- \\ Hematology-Oncology, Sayed-ol- \\ Shohada Hospital, Isfahan University \\ of Medical Sciences, Isfahan, Iran; \\ ${ }^{3}$ Gene Expression - Microarrays \\ Laboratory, Bambino Gesù Children's \\ Hospital-Istituto di Ricovero e Cura \\ a Carattere Scientifico (IRCCS), \\ Rome, Italy \\ *These authors contributed equally \\ to the manuscript
}

Purpose: The aim of this work was to study the correlation between the expressions of the $A B C A 2$ and $A B C A 3$ genes at the mRNA and protein levels in children with acute lymphoblastic leukemia (ALL) and the effects of this association on multidrug resistance (MDR).

Materials and methods: Sixty-nine children with de novo ALL and 25 controls were enrolled in the study. Mononuclear cells were isolated from the bone marrow. The mRNA levels of $A B C A 2$ and $A B C A 3$ were measured by real-time polymerase chain reaction (PCR). Samples with high mRNA levels were assessed for respective protein levels by Western blotting. Following the first year of treatment, persistent monoclonality of T-cell gamma receptors or immunoglobulin $\mathrm{H}(\mathrm{IgH})$ gene rearrangement was assessed and considered as the MDR. The tertiary structure of ABCA2 was predicted using Phyre2 and I-TASSER web systems and compared to that of $\mathrm{ABCA} 3$, which has been previously reported. Molecular docking was performed using DOCK 6.7.

Results: Real-time quantitative PCR (qRT-PCR) showed high levels of $A B C A 2$ and $A B C A 3$ mRNAs in 13 and 17 samples, respectively. Among them, five and eight individuals demonstrated high levels of ABCA2 and ABCA3, respectively. Response to chemotherapy was significantly decreased $(P=0.001)$ when the mRNA and protein of both genes were overexpressed compared to individuals with high transcriptional levels of either $A B C A 2$ or $A B C A 3$ alone. Close similarity between $\mathrm{ABCA} 2$ and $\mathrm{ABCA} 3$ structures was revealed by protein tertiary structure prediction, whereas molecular docking analysis suggested similar binding of chemotherapy drugs and therefore a potentially similar role in determining the MDR.

Conclusion: Our findings suggested, for the first time, that quantification of the protein level of ABCA2 and ABCA3 transporters had a prognostic impact on pediatric ALL MDR. Furthermore, the tertiary structure of $\mathrm{ABCA} 2$ was predicted for the first time, and docking analysis revealed a possible compensatory effect between $\mathrm{ABCA} 2$ and $\mathrm{ABCA} 3$ transporters, which may contribute to the efflux of cytotoxic drugs and, ultimately, to chemoresistance.

Keywords: $\mathrm{ABCA} 2$ transporter, $\mathrm{ABCA} 3$ transporter, multidrug resistance, childhood acute lymphoblastic leukemia, molecular docking, tertiary structure

\section{Introduction}

ALL is one of the most common types of cancer in children younger than 15 years. ${ }^{1,2}$ The peak incidence of ALL is between 2 and 5 years of age. ${ }^{3}$ Despite the successes achieved in the treatment of childhood ALL in the past 4 decades, relapse was observed in $\sim 20 \%$ of cases. ${ }^{4,5}$ The most important cause of relapse is resistance to 
chemotherapy medications, ${ }^{6,7}$ which is often attributed to genes with MDR. MDR is generated by mechanisms such as the increased efflux of a wide range of chemotherapeutics from the cells. ${ }^{7-9}$ Increased expression of ABC membrane transporters leads to activation of this mechanism. ${ }^{8,10-12}$ One of the known members of this family, which belongs to the ABCA subfamily, is the endolysosomal protein named ABCA2, which is associated with lipid transport and drug resistance. ${ }^{13-15}$ This protein is located on inner vesicles, ${ }^{16}$ including the endoplasmic reticulum, ${ }^{13,17,18}$ the trans-Golgi network, ${ }^{19}$ late endosomes and lysosomes. ${ }^{20,21}$ Another member of the ABC family is ABCA3. This protein is expressed in the cytoplasmic membrane and cell's inner compartments such as the endosome, lysosome and lamellar bodies. ${ }^{22}$

The role of $\mathrm{ABCA} 2$ and $\mathrm{ABCA} 3$ in drug transport is not entirely clear, but much of the evidence suggests that these carrier proteins have a role in MDR by causing an accumulation of drugs in the lysosomes and possibly their efflux from the cell. ${ }^{23,24}$ The mRNA expression studies of ABCA2 and ABCA3 have shown that these genes are involved in drug resistance in adult T-ALL, acute myeloid leukemia (AML) and chronic myeloid leukemia (CML). ${ }^{25-28}$ In addition, a recent study performed by our group has shown that four $\mathrm{ABC}$ transporters, including $\mathrm{ABCA} 2$ and $\mathrm{ABCA} 3$, are related to poor prognosis in childhood $\mathrm{ALL}^{29,30}$ and have a direct relationship with MRD persistence after 1 year of treatment. ${ }^{30}$ However, some cases with high ABCA2 or ABCA3 expression at the mRNA levels had good response to treatment, and some cases without any overexpression of these genes were resistant to therapy. While the latter may occur due to the multifactorial nature of drug resistance, which can be attributed to other mechanisms apart from the overexpression of MDR genes, the former finding raises questions about the negative role of the aforementioned ABC transporters in MDR ALL. Previous studies show that the expression of a gene at the mRNA level is not always associated with its expression at the protein level. ${ }^{31,32}$ However, no published data were found to discuss either the relationship between the mRNA and protein levels of ABCA transporters or the significance of this correlation in MDR. The aim of this study was, therefore, to investigate the plot of protein versus mRNA expression levels for the $A B C A 2$ and $A B C A 3$ genes, evaluate the significance of this correlation in MDR of childhood ALL in order to better identify the high- and low-risk patients, and find a better approach to treatment. On the other hand, the functional activity of $\mathrm{ABCA} 2$ and $\mathrm{ABCA} 3$ proteins was investigated regarding chemotherapeutic medicines using molecular docking analyses.

\section{Materials and methods Materials}

Immunophenotyping was performed by flow cytometry, and related antibodies were purchased from Dako Denmark A/S (Glostrup, Denmark); Lymphoprep ${ }^{\mathrm{TM}}$, RNX-Plus and cDNA synthesis kits were from Axis-Shield (Oslo, Norway), Cinnagen (Tehran, Iran) and Fermentas (Waltham, MA, USA). Real-time PCR kit was purchased from TaKaRa (Otsu, Japan); RIPA lysis buffer was from Sigma-Aldrich (St Louis, MO, USA) and protease inhibitor cocktail was purchased from Melford (Melford, UK). Protein ladder and PVDF blotting membrane were from Thermo Fisher Scientific (Waltham, MA, USA) and GE Healthcare (Buckinghamshire, UK), respectively. Goat anti-ABCA2 polyclonal antibody and goat anti-ABCA3 polyclonal antibody were purchased from Santa Cruz Biotechnology Inc., (Dallas, TX, USA); rabbit anti-goat IgG-HRP was from Sigma-Aldrich and mouse anti-GAPDH monoclonal antibody was purchased from EMD Millipore (Billerica, MA, USA). Goat anti-mouse IgG-HRP was purchased from Dako Denmark A/S and ECL solution was from Bio-Rad Laboratories Inc., (Hercules, CA, USA).

\section{Methods}

\section{Sampling and RNA extraction}

The study included all children who were diagnosed to be at risk for leukemia in the Seyed-ol-Shohada Hospital, Isfahan, during the period from 2012 to 2016. Philadelphia-positive leukemia, infantile leukemia, mixed lineage leukemia and Burkitt-type leukemia were excluded from the research because of the nonsimilar type of treatment protocol applied. This research was permitted and approved by the ethics committee of Isfahan University of Medical Sciences (protocol number 192018). Informed written consents were obtained from the children's parents prior to participation in the study. Following diagnosis, $1-2 \mathrm{~mL}$ of heparinized bone marrow was sent to the Cellular and Molecular Biology Laboratory of University of Isfahan on ice for further studies. Bone marrow samples from children without evidence of any cancer (including leukemia) were selected as controls. Extraction of mononuclear cells was performed using a protocol based on the Lymphoprep ${ }^{\mathrm{TM}}$ Kit. The total RNA was extracted using the RNX-Plus kit and $2 \mu \mathrm{g}$ of total RNA was used for cDNA synthesis by a cDNA synthesis kit, in accordance with the specific temperature protocol (sequentially, 5 minutes at $25^{\circ} \mathrm{C}, 60$ minutes at $42^{\circ} \mathrm{C}$, and 5 minutes at $70^{\circ} \mathrm{C}$ ). The cDNA was then stored at $-20^{\circ} \mathrm{C}$ for further studies. Patients were treated based on the Australian 
and New Zealand Children's Cancer Study Group's ALL Study 8 protocol (http://www.anzctr.org.au/trial view. aspx?ID=1568). Bone marrow samples were evaluated for monoclonality (IgH or T-cell gamma receptor gene rearrangement) at diagnosis and again at the end of the first year of treatment using PCR analysis. Persistent monoclonality of T-cell gamma receptors or $\mathrm{IgH}$ gene rearrangement after 1 year of treatment, or observation of any sign of leukemia relapse before this time, was considered as MDR. Twentyfive children, with no evidence of malignancy in subsequent studies, were used as controls.

\section{qRT-PCR analysis}

The housekeeping gene $G A P D H$ was used as an endogenous control to study the relative expression of $A B C A 2$ and $A B C A 3$ mRNAs. The sequences of the primers used in this study are reported in Table 1. Real-time PCR was performed using the real-time PCR kit (Applied Biosystems Step One ${ }^{\mathrm{TM}}$ Real-Time PCR system). Briefly, $1 \mu \mathrm{L}$ of $0.01 \mu \mathrm{g} / \mathrm{mL}$ of the synthesized cDNA, $0.4 \mu \mathrm{L}$ of $100 \mathrm{nM}$ forward and reverse primers, $5 \mu \mathrm{L}$ of SYBR green Master Mix and $3.2 \mu \mathrm{L}$ of $\mathrm{ddH}_{2} \mathrm{O}$ were added to the real-time tubes. Then, qRT-PCR was performed in triplicate according to the protocol that included a preincubation at $95^{\circ} \mathrm{C}(5$ minutes $)$, denaturation at $95^{\circ} \mathrm{C}$ (20 seconds), annealing at $60^{\circ} \mathrm{C}$ (30 seconds) and product expansion at $72^{\circ} \mathrm{C}$ ( 25 seconds). Relative expression levels were calculated using the $2^{-\Delta \Delta \mathrm{Ct}}$ method.

\section{Cell lysis and protein extraction}

After assessing the expression level of $A B C A 2$ and $A B C A 3$ mRNAs of the patients' and controls' samples, cells belonging to patients with high levels of one or both mRNAs were chosen for Western blotting analysis. Twelve randomly selected control samples were pooled and used as a negative control sample for the aforementioned assay. Cell lysis was performed using RIPA lysis buffer and protease inhibitor cocktail after freezing and thawing cells three times. To conduct freezing and thawing, $30 \mu \mathrm{L}$ PBS solution was added to the cells and cooled at $-70^{\circ} \mathrm{C}$ for 10 minutes. Frozen tubes were then placed in $37^{\circ} \mathrm{C}$ water until the cells melted completely. Cells were centrifuged for 10 minutes at $250 \times g$ and $4{ }^{\circ} \mathrm{C}$; the PBS supernatant was discarded and the cells were incubated for 30 minutes on ice $\left(4^{\circ} \mathrm{C}\right)$ in cold lysis buffer (using $1 \mathrm{~mL}$ RIPA buffer and $10 \mu \mathrm{L}$ protease inhibitor cocktail for every $10^{7}$ cells). Tubes were then centrifuged at $8,000 \times g$ for 10 minutes at $4^{\circ} \mathrm{C}$, and the supernatant was stored in small volumes at $-70^{\circ} \mathrm{C}$ after determining the protein concentration using the Bradford technique.

\section{SDS-PAGE and Western blotting}

The molecular weights of ABCA2 and ABCA3 proteins are $270 \mathrm{kDa}$ and $191 \mathrm{kDa}$, respectively; therefore, a 7.5\% resolving gel was prepared for the SDS-PAGE assay. Mouse antiGAPDH monoclonal antibody was used as loading control. An amount of $21.5 \mu \mathrm{g}$ of proteins extracted from the samples was loaded with the required volume of loading buffer after boiling the proteins for $5-10$ minutes at $100^{\circ} \mathrm{C}$, and SDS-PAGE was performed using a protein marker. Proteins were then transferred from the gel to PVDF membranes. Nonspecific binding sites were blocked using 4\% BSA in PBS solution overnight. Membranes were then treated with primary antibodies for 2 hours and with secondary antibodies for 1 hour. Goat antiABCA2 and anti-ABCA3 polyclonal primary antibodies and mouse anti-GAPDH monoclonal antibodies were used at 1:200 dilutions. Rabbit anti-goat IgG-HRP and goat anti-mouse IgG-HRP secondary antibodies were used at 1:2,500 dilutions. Incubations were performed with mild shaking. Washing was done three times with $0.1 \%$ Tween-20 in PBS- $1 \times$ solution, each time for 15 minutes on a shaker. Proteins were detected on sensitive radiology films in a dark room using ECL solution. Finally, we evaluated the relationship between the expression of the genes at the protein level and MDR.

\section{Tertiary structure prediction}

The 2,436 amino acid sequence of ABCA2 (accession: AAK14334.1, GI: 13173186) was retrieved from the National

Table I Primer sequences of $A B C A 2, A B C A 3$ and $G A P D H$

\begin{tabular}{lllll}
\hline Gene & Primer sequence (5' to 3') & $\begin{array}{l}\text { Primer length } \\
\text { (base pairs) }\end{array}$ & $\begin{array}{l}\text { Amplicon length } \\
\text { (base pairs) }\end{array}$ & $\begin{array}{c}\text { Tm } \\
\text { GC\% }\end{array}$ \\
\hline ABCA2 & F:CCGCACCATCCTTCTGTCCACCCACC & 26 & 263 & 65.38 \\
& R:TGCGGATGAACTGGGACACCTGGAGC & 26 & & 61.54 \\
ABCA3 & F:GGCCATCATCATCACCTCCCACAGCA & 26 & 177 & 57.79 \\
& R:AGCGCCTCCTGTTGCCCTTCACTCTG & 26 & 106 & 66.7 \\
GAPDH & F:GCCCCAGCAAGAGCACAAGAGGAAGA & 26 & 68.7 & 68.64 \\
& R:CATGGCAACTGTGAGGAGGGGAGATT & 26 & 57.69 \\
\hline
\end{tabular}

Abbreviations: F, forward; GAPDH, glyceraldehyde 3-phosphate dehydrogenase; $R$, reverse; $T m$, melting temperature. 
Center for Biotechnology Information (NCBI) (https://www. ncbi.nlm.nih.gov) in FASTA format, and the tertiary structure of this protein was predicted by Phyre $2,{ }^{33}$ similarly to methods described for $\mathrm{ABCA} 3{ }^{34}$ Briefly, the $\mathrm{ABCA} 2$ protein sequence was divided into two overlapping sequence segments and independently predicted. The final model was obtained by reconstructing the two models using the University of California, San Francisco (UCSF) Chimera package (https:// www.cgl.ucsf.edu/chimera/). ${ }^{35}$ Chimera was developed by the Resource for Biocomputing, Visualization, and Informatics at the UCSF (supported by the National Institute of General Medical Sciences [NIGMS] P41-GM103311).

\section{Molecular docking}

To demonstrate the similarities of drug binding between ABCA2 and ABCA3, we downloaded the coordinate files of estramustine, doxorubicin, methotrexate, vincristine, 6-mercaptopurine and prednisolone chemotherapy drugs from the PubChem database (https://pubchem.ncbi.nlm.nih.gov/). Molecular docking (flexible ligands) was performed using DOCK 6.7 (UCSF; http://dock.compbio.ucsf.edu/DOCK 6/ index.htm) on a multiple-processor workstation. ${ }^{36}$

\section{Statistical analysis}

Statistical analysis was performed using SPSS 20.0 and chi-square test to investigate the relationship between ABCA2 and $\mathrm{ABCA} 3$ protein expression and positive MDR.

\section{Results}

Sixty-nine de novo non-Philadelphia-positive ALL patients, including nine T-cell ALL and 60 pre-B-cell ALL patients, were entered into the study. There were 29 females and 40 males, with the mean age of $4.8 \pm 2.5$ years (mean $\pm \mathrm{SD}$ ). The mean age of the controls was similar $(6 \pm 4.1$ years $)$ (mean $\pm \mathrm{SD}, P=0.251$ ). After the first induction, one patient with pre-B-cell ALL and $\mathrm{t}(4 ; 11)$ chromosomal translocation did not go into remission and was diagnosed as resistant to treatment. Three patients relapsed before the end of the first year (two with pre-B-cell ALL and one patient with T-cell leukemia). Overall, three relapsed patients and 19 MRD-positive patients who maintained monoclonality were categorized as the MDR patient group.

\section{Real-time PCR and immunoblotting analysis}

We found that 13 and 17 of the 69 patients with a diagnosis of de novo ALL had an increased level of $A B C A 2$ and $A B C A 3$ mRNA, respectively (compared to controls). Figure 1 shows a representative selection of ALL patients, wherein the bands of $A B C A 2$ and $A B C A 3$ mRNA are clearly visible compared to the nontemplate control. However, Western blot analysis revealed that only five out of $13(38.5 \%)$ and eight out of $17(47.1 \%)$ patients additionally had a significant expression of the corresponding $\mathrm{ABCA} 2$ and $\mathrm{ABCA} 3$ proteins, respectively (Table 2 and Figure 2).

The incidence of MDR was significantly higher in patients with ABCA2 overexpression at both mRNA and protein levels compared to those with normal $A B C A 2$ gene expression $(100 \%$ vs $19.6 \% ; P=0.0001)$. There was no significant difference in drug resistance between patients with normal gene expression at the mRNA level and those who overexpressed ABCA2 at the mRNA level but not so at the protein level (19.6\% vs 37.5\%; $P=0.253)$.

An increased expression level of ABCA3 in 17 out of 69 children with ALL, compared to controls, was observed (Figure 1). However, in nine patients (53\%), no visible band was demonstrated in Western blot assay (Table 2B, Figure 2). We found a significant difference in drug resistance between patients with gene overexpression at both mRNA and protein levels and those without gene expression at mRNA levels ( $87.5 \%$ vs $19.2 \% ; P=0.0001)$. There was no significant difference in drug resistance between patients who overexpressed ABCA3 at the mRNA level without protein expression and those without gene overexpression at the mRNA level (22.2\% vs $19.2 \% ; P=0.838)$.

Results showed that among the 69 patients included in this study, 12 cases (17.4\%) expressed either ABCA2 or

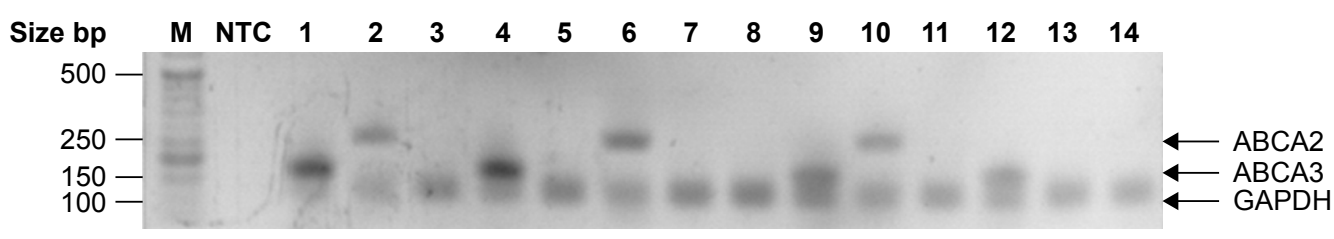

Figure I Results obtained by RT-PCR amplification of ABCA2 and ABCA3 in a representative selection of ALL patients.

Notes: Real-time PCR was performed in triplicate for each sample. To confirm the purity and correct size of the qRT-PCR products, the target and the housekeeping GAPDH gene, random amplicons were loaded on an agarose gel. The gel was stained with ethidium bromide and photographed.

Abbreviations: ABC, ATP-binding cassette; ALL, acute lymphoblastic leukemia; GAPDH, glyceraldehyde 3-phosphate dehydrogenase; M, molecular weight marker; NTC, nontemplate control; PCR, polymerase chain reaction; qRT-PCR; quantitative reverse transcriptase PCR. 
Table 2 The expression profiles of $A B C A 2$ and $A B C A 3$, separately $(\mathbf{A}, \mathbf{B})$ and together $(\mathbf{C})$ at the mRNA and protein levels in 69 patients with de novo ALL

\begin{tabular}{|c|c|c|c|}
\hline \multicolumn{4}{|l|}{$\bar{A}$} \\
\hline ABCA2 & MDR $^{+}$ & MDR $^{-}$ & Total \\
\hline $\mathrm{mRNA}^{-}$, protein $^{-}$ & II (19.6\%) & 45 (80.4\%) & 56 \\
\hline $\mathrm{mRNA}^{+}$, protein- & $3(37.5 \%)$ & 5 (62.5\%) & 8 \\
\hline $\mathrm{mRNA}^{+}$, protein ${ }^{+}$ & $5(100 \%)$ & $0(0 \%)$ & 5 \\
\hline Total & 19 (27.5\%) & $50(72.5 \%)$ & 69 \\
\hline \multicolumn{4}{|l|}{ B } \\
\hline ABCA3 & MDR $^{+}$ & MDR $^{-}$ & Total \\
\hline $\mathrm{mRNA}^{-}$, protein - & $10(19.2 \%)$ & 42 (80.8\%) & 52 \\
\hline $\mathrm{mRNA}^{+}$, protein ${ }^{-}$ & $2(22.2 \%)$ & 7 (77.8) & 9 \\
\hline mRNA $^{+}$, protein ${ }^{+}$ & 7 (87.5\%) & I (I2.5\%) & 8 \\
\hline Total & 19 (27.5\%) & $50(72.5 \%)$ & 69 \\
\hline \multicolumn{4}{|l|}{$\mathbf{C}$} \\
\hline \multicolumn{4}{|l|}{ АВСA3 } \\
\hline $\mathrm{mRNA}^{-}$, protein - & $4(9.3 \%)$ & 39 (90.7\%) & 43 \\
\hline $\mathrm{mRNA}^{+}$, protein ${ }^{-}$ & $4(28.5 \%)$ & 10 (71.5\%) & 14 \\
\hline $\mathrm{mRNA}^{+}$, protein $^{+}$ & II (9I.5\%) & I (8.5\%) & 12 \\
\hline Total & 19 (27.5\%) & 50 (72.5\%) & 69 \\
\hline
\end{tabular}

Notes: mRNA ${ }^{-}$indicates no overexpression of mRNA compared to the control group; protein ${ }^{-}$indicates no band was observed in Western blotting.

Abbreviations: ALL, acute lymphoblastic leukemia; MDR, multidrug resistance.

$\mathrm{ABCA} 3$ at the protein levels. From this population, 11 cases (91.7\%) displayed resistance to chemotherapy (Table 2C). There was a significant difference in response to therapy between patients who expressed $\mathrm{ABCA} 2 / \mathrm{ABCA} 3$ at the protein level compared with those without $\mathrm{ABCA} 2 / \mathrm{ABCA} 3$ protein expression $(91.7 \%$ vs $14 \% ; P=0.001)$.

\section{Alternative risk factors}

The mRNA or protein expression levels of ABCA2 or ABCA3 had no significant relationship with underlying factors such as age, sex, WBC and platelet counts, hepatosplenomegaly at diagnosis, and subtypes of the disease (including T-cell ALL and pre-B-cell ALL). No correlation between the aforementioned factors and response to treatment was observed.

Tertiary structure prediction and molecular docking of

\section{$A B C A 2$ and $A B C A 3$}

Previous clinical studies have shown that estramustine is sequestered and effluxed by ABCA2 in resistant ovarian carcinoma. ${ }^{13,37}$ Docking analysis performed on a predicted model of ABCA2 suggested that ABCA2 is able to bind estramustine (docking grid energy equal to $-42.395 \mathrm{kcal} / \mathrm{mol}$ ) (data not shown). The overlap between the ABCA2 and ABCA3 models obtained by Phyre2 outlined the presence of similar domains (ie, transmembrane helixes and nucleotidebinding domains) (Figure 3A). This finding was also suggested by visually inspecting the ab initio model obtained by I-TASSER on ABCA3 (Figure 3B) and the structure of ABCA2 obtained by Phyre2. Figure 3C shows ABCA2, as a representative example, used for docking calculation, surrounded by the corresponding surface (in green) and water molecules (in cyan). The $20 \mu \mathrm{m}$ box around the active site of the protein (gray lines) has been chosen for grid calculation and docking. Docking analyses were performed for $\mathrm{ABCA} 2$ and $\mathrm{ABCA} 3$ protein models. Five chemotherapy drugs, doxorubicin, methotrexate, vincristine, 6-mercaptopurine and prednisolone, were used as ligands. Doxorubicin was depicted as a representative example (Figure 4). Data showed almost identical docking results for $\mathrm{ABCA} 2$ and $\mathrm{ABCA} 3$. We found that doxorubicin possessed a docking grid energy of $-42.093 \mathrm{kcal} / \mathrm{mol}$, methotrexate of $-48.092 \mathrm{kcal} / \mathrm{mol}$, vincristine of $-33.796 \mathrm{kcal} / \mathrm{mol}$, 6-mercaptopurine of $-17.831 \mathrm{kcal} / \mathrm{mol}$, and prednisolone of $-34.312 \mathrm{kcal} / \mathrm{mol}$.

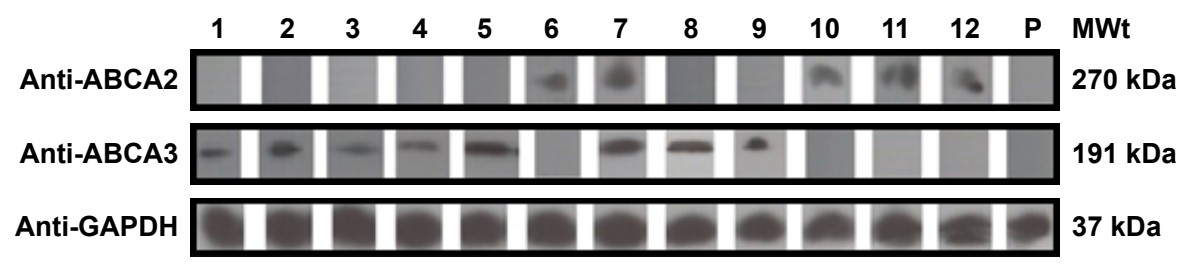

Figure $2 A B C A 2$ and $A B C A 3$ protein expression of samples with a high $A B C A 2 / A B C A 3$ mRNA expression.

Notes: Mononuclear cell lysis and extraction of total protein was performed on blood samples of de novo ALL patients with high expression of $A B C A 2$ and $A B C A 3$ at mRNA levels compared to controls. Accordingly, $21.5 \mu \mathrm{g}$ of the extracted protein was loaded into the wells and Western blotting was performed following SDS-PAGE using goat anti-human $\mathrm{ABCA} 2$ and $\mathrm{ABCA} 3$ polyclonal antibodies, respectively. PVDF membranes were treated with related secondary antibody and exposed to ECL solution. Out of $12 \mathrm{MRD}^{+}$patients, seven showed visible bands corresponding to high expression levels of $\mathrm{ABCA} 3$ protein with an MWt of $19 \mathrm{l} \mathrm{kDa}$, and five showed visible bands corresponding to high expression levels of $A B C A 2$ protein with an MWt of $270 \mathrm{kDa}$. One MRD patient (patient number II) showed high expression levels of $A B C A 3$. Each lane corresponds to an individual $\mathrm{ABCA} 2$ or $\mathrm{ABCA} 3$ mRNA ${ }^{+}$patient and is labeled by numbers. Probing the blots with mouse anti-human $\mathrm{GAPDH}$ monoclonal antibody showed identical amounts of loaded proteins. P indicates a pool of 12 control samples.

Abbreviations: ECL, enhanced chemiluminescence; GAPDH, glyceraldehyde 3-phosphate dehydrogenase; MRD, minimal residual disease; MWt, molecular weight; PVDF, polyvinylidene difluoride; SDS-PAGE, sodium dodecyl sulfate polyacrylamide gel electrophoresis. 
A

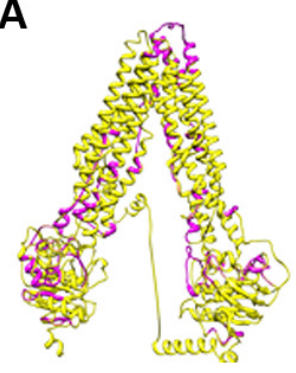

B

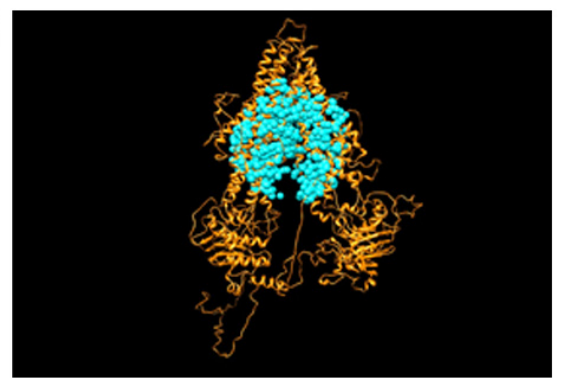

C

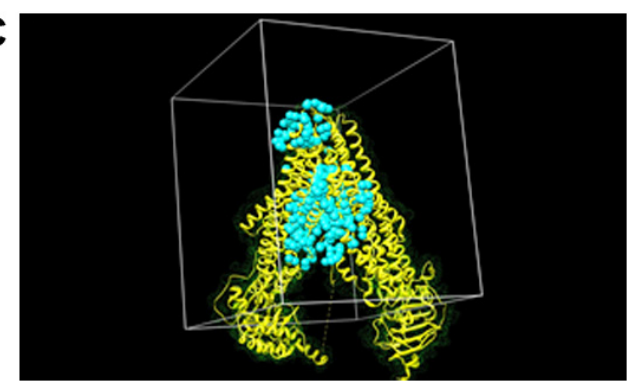

Figure 3 Tertiary structures of $A B C A 2$ and $A B C A 3$.

Notes: (A) Comparative structural analysis of ABCA2 (purple) and ABCA3 (yellow) models predicted by Phyre2 showed close similarity. (B) ABCA3 model obtained by I-TASSER ab initio method (orange) and the water molecules (cyan) within the active site. (C) ABCA2 active site used for grid calculations and docking analysis. ABCA2 model (yellow), ABCA2 molecular surface (green), water molecules (cyan) and ABCA2 active site (gray box).

\section{Discussion}

Several studies have suggested the possible role of the $\mathrm{ABC}$ transporter genes $\mathrm{ABCA} 2$ and $\mathrm{ABCA} 3$ in several malignancies in terms of contributing to MDR. ${ }^{38,39}$ However, other studies underestimate the impact of these transporters on cancer and the MDR phenomenon. ${ }^{25,40}$ The reason for this controversy might be the discordance between the gene expression at the mRNA and protein levels. In the current study, we examined ABCA2 and ABCA3 expressions in childhood ALL at the mRNA level with respect to the protein level. Results concerning the prevalence of the overexpression of these genes at the mRNA level mirrored those of our previous study $(18.84 \%$ and $24.64 \%$ of ALL patients for $\mathrm{ABCA} 2$ and $\mathrm{ABCA} 3$, respectively). However, poor response to treatment was not always correlated with gene overexpression; five out of 13 patients with high mRNA but low protein levels of $\mathrm{ABCA} 2$, and seven out of 17 patients with high mRNA but low protein levels of ABCA3, had positive responses to treatment, similar to de novo patients with low mRNA transcript levels (Table 2A and B). On the other hand, all except one of the 12 patients with increased levels of $A B C A 2$ and/or ABCA3 protein levels among the 69 de novo ALL patients developed MDR, implying the critical role of these transporters in refractory pediatric ALL (Table 2C). Out of 26 patients with an overexpression of $A B C A 2 / A B C A 3$ mRNA, 14 patients (53.8\%) did not express high levels of the corresponding protein, and $71.4 \%$ of them had a positive response to therapy (Table 2C). If clinicians classify ALL patients as "high risk" only considering their $A B C A 2 / A B C A 3$ mRNA expression values, without taking into consideration the absence of the corresponding protein level, an unnecessary intensive treatment will follow. Alternative diagnostic strategies might simplify the therapy (ie, shorter chemotherapy cycles with a consequent earning in terms of therapeutic costs) and a reduced number of complications.

These data suggest, for the first time, a robust negative prognostic value for patients with a high expression of either $\mathrm{ABCA} 2$ or $\mathrm{ABCA} 3$ (or both) at the mRNA and protein levels, simultaneously. This finding should be considered in therapeutic strategies applied for childhood ALL.
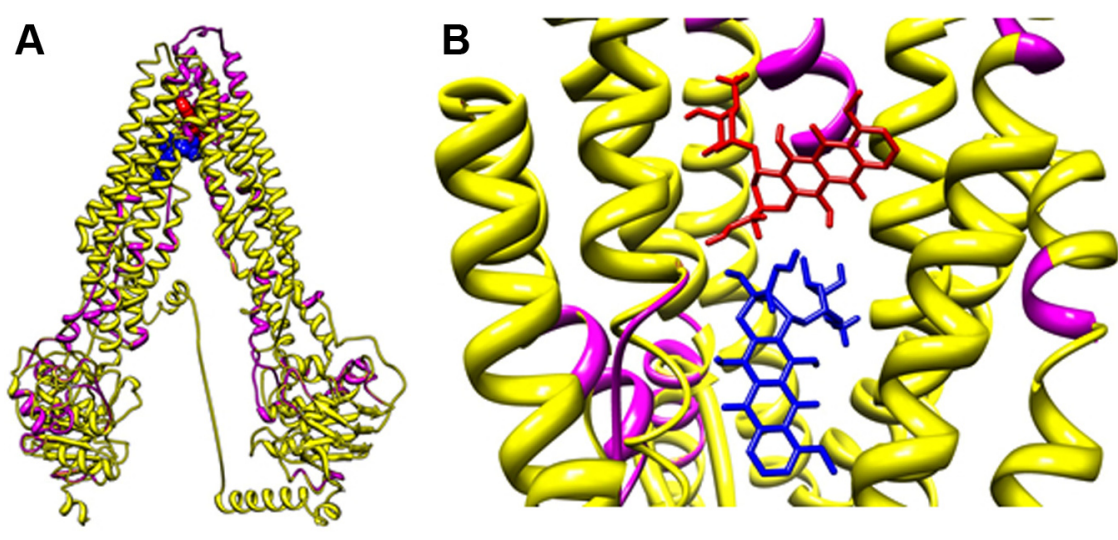

Figure 4 Molecular docking analyses of $A B C A 2 / A 3$ models shown in zoomed out (A) and zoomed in (B) images.

Notes: Doxorubicin is depicted as a representative ALL antineoplastic drug and colored arbitrarily according to the heteroatom. $A B C A 2$ (purple); $A B C A 3$ (yellow). Abbreviation: ALL, acute lymphoblastic leukemia. 
A possible compensatory effect between $\mathrm{ABCA} 2$ and $\mathrm{ABCA} 3$ transporters was previously proposed, through which, downregulation of one transporter leads to the upregulation of the other. ${ }^{27}$ In the current study, we confirmed these findings and observed the existence of an interchangeable pattern of protein expression between ABCA3 and $\mathrm{ABCA} 2$, at least in some of our patients with poor response to therapy. Four patients with MDR showed high protein levels of ABCA2 and low protein levels of ABCA3, simultaneously. In addition, seven MDR patients displayed high protein levels of $A B C A 3$ and low protein levels of $A B C A 2$ (Figure 2). Functional similarity of these two transporters has been suggested by examining the models of ABCA2 and $\mathrm{ABCA} 3$ and the corresponding ligands used as chemotherapy drugs (reported in the National Cancer Institute [NCI] database) ${ }^{27}$ Computational prediction studies and docking analyses were performed to investigate this hypothesis and suggest a mutualistic role of $\mathrm{ABCA} 2$ and $\mathrm{ABCA} 3$ transporters for chemotherapy drug efflux. To the best of our knowledge, this is the first study reporting the model of ABCA2 protein and revealing its similarity to $\mathrm{ABCA} 3$.

Finally, although much has been explored in this regard, the exact mechanism through which $\mathrm{ABCA} 2$ and $\mathrm{ABCA} 3$ transporters contribute to chemoresistance is still to be fully established. Moreover, investigating larger populations of ALL patients in prospective cohort studies may help emphasize the validity of results provided in this study.

\section{Abbreviations}

ABC, ATP-binding cassette; ALL, acute lymphoblastic leukemia; BSA, bovine serum albumin; cDNA, complementary DNA; ECL, enhanced chemiluminescence; GAPDH, glyceraldehyde 3-phosphate dehydrogenase; $\mathrm{GC} \%$, guaninecytosine percentage; GI, GenInfo Identifier; HRP, horseradish peroxidase; MDR, multidrug resistance; $M R D$, minimal residual disease; PBS, phosphate-buffered saline; PCR, polymerase chain reaction; $\mathrm{PVDF}$, polyvinylidene difluoride; qRT-PCR, quantitative reverse transcription polymerase chain reaction; RIPA, radioimmunoprecipitation assay; SDS-PAGE, sodium dodecyl sulfate polyacrylamide gel electrophoresis; WBC, white blood cell.

\section{Acknowledgments}

We thank Mansoureh Entezar-e-Ghaem for providing insight and expertise that greatly assisted the research, and Hadi Moafi (University of Pecs Medical School, Hungary) for editing the paper and helpful comments. This work was supported by a research grant from the Isfahan University of Medical Sciences to AMo (192018) and postgraduate research grants to NA (92/14505) and ZKD (92/14512) from the University of Isfahan.

\section{Author contributions}

All authors contributed toward data analysis, drafting and critically revising the paper and agree to be accountable for all aspects of the work.

\section{Disclosure}

The authors report no conflicts of interest in this work.

\section{References}

1. Sousa DWL, Ferreira FVA, Félix FHC, Lopes MVO. Acute lymphoblastic leukemia in children and adolescents: prognostic factors and analysis of survival. Rev Bras Hematol Hemoter. 2015;37(4):223-229.

2. Belson M, Kingsley B, Holmes A. Risk factors for acute leukemia in children: a review. Environ Health Perspect. 2007;115(1):138-145.

3. Seghatoleslam A, Monabati A, Bozorg-Ghalati F, et al. Expression of UBE2Q2, a putative member of the ubiquitin-conjugating enzyme family in pediatric acute lymphoblastic leukemia. Arch Iran Med. 2012; 15(6):352-355.

4. Locatelli F, Schrappe M, Bernardo ME, Rutella S. How I treat relapsed childhood acute lymphoblastic leukemia. Blood. 2012;120(14): 2807-2816.

5. Hayati H, Kebriaeezadeh A, Nikfar S, Mehrvar A. Cost-analysis of treatment of pediatrics acute lymphoblastic leukemia based on ALLBFM protocol. Int J Pediatr. 2016;4(9):3381-3389.

6. Wojtuszkiewicz A, Raz S, Stark M, et al. Folylpolyglutamate synthetase splicing alterations in acute lymphoblastic leukemia are provoked by methotrexate and other chemotherapeutics and mediate chemoresistance. Int J Cancer. 2016;138(7):1645-1656.

7. Li W, Zhang H, Assaraf YG, et al. Overcoming ABC transportermediated multidrug resistance: molecular mechanisms and novel therapeutic drug strategies. Drug Resist Updat. 2016;27:14-29.

8. Shukla S, Chen Z-S, Ambudkar SV. Tyrosine kinase inhibitors as modulators of ABC transporter-mediated drug resistance. Drug Resist Updat. 2012;15(1-2):70-80.

9. Chauhan PS, Bhushan B, Singh L, et al. Expression of genes related to multiple drug resistance and apoptosis in acute leukemia: response to induction chemotherapy. Exp Mol Pathol. 2012;92(1):44-49.

10. Hlavác V, Brynychová V, Václavíková R, et al. The expression profile of ATP-binding cassette transporter genes in breast carcinoma. Pharmacogenomics. 2013;14(5):515-529.

11. Fukuda Y, Schuetz JD. ABC transporters and their role in nucleoside and nucleotide drug resistance. Biochem Pharmacol. 2012;83(8):1073-1083.

12. Fletcher JI, Haber M, Henderson MJ, Norris MD. ABC transporters in cancer: more than just drug efflux pumps. Nat Rev Cancer. 2010;10(2): $147-156$.

13. Davis W, Boyd JT, Ile KE, Tew KD. Human ATP-binding cassette transporter-2 (ABCA2) positively regulates low-density lipoprotein receptor expression and negatively regulates cholesterol esterification in Chinese hamster ovary cells. Biochim Biophys Acta. 2004;1683(1):89-100.

14. Mack J, Beljanski V, Tew K, Townsend D. The ATP-binding cassette transporter ABCA2 as a mediator of intracellular trafficking. Biomed Pharmacother. 2006;60(9):587-592.

15. Aberuyi N, Rahgozar S, Moafi A. The role of ATP-binding cassette transporter A2 in childhood acute lymphoblastic leukemia multidrug resistance. Iran J Ped Hematol Oncol. 2014;4(3):118.

16. Broccardo C, Nieoullon V, Amin R, et al. ABCA2 is a marker of neural progenitors and neuronal subsets in the adult rodent brain. JNeurochem. 2006;97(2):345-355. 
17. Michaki V, Guix FX, Vennekens K, et al. Down-regulation of the ATPbinding cassette transporter 2 (Abca2) reduces amyloid- $\beta$ production by altering Nicastrin maturation and intracellular localization. $J$ Biol Chem. 2012;287(2):1100-1111.

18. Abuznait AH, Kaddoumi A. Role of ABC transporters in the pathogenesis of Alzheimer's disease. ACS Chem Neurosci. 2012;3(11): $820-831$.

19. Li G, Gu HM, Zhang DW. ATP-binding cassette transporters and cholesterol translocation. IUBMB Life. 2013;65(6):505-512.

20. Sakai H, Tanaka Y, Tanaka M, et al. ABCA2 deficiency results in abnormal sphingolipid metabolism in mouse brain. J Biol Chem. 2007; 282(27):19692-19699.

21. Tarling EJ, de Aguiar Vallim TQ, Edwards PA. Role of ABC transporters in lipid transport and human disease. Trends Endocrinol Metab. 2013;24(7):342-350.

22. Yamano G, Funahashi H, Kawanami O, et al. ABCA3 is a lamellar body membrane protein in human lung alveolar type II cells. FEBS Lett. 2001;508(2):221-225.

23. Albrecht C, Viturro E. The ABCA subfamily - gene and protein structures, functions and associated hereditary diseases. Pflügers Arch. 2007;453(5):581-589.

24. Mack JT, Brown CB, Tew KD. ABCA2 as a therapeutic target in cancer and nervous system disorders. Expert Opin Ther Targets. 2008; 12(4):491-504.

25. Gillet JP, Efferth T, Steinbach D, et al. Microarray-based detection of multidrug resistance in human tumor cells by expression profiling of ATP-binding cassette transporter genes. Cancer Res. 2004;64(24): 8987-8993.

26. Steinbach D, Gillet J-P, Sauerbrey A, et al. ABCA3 as a possible cause of drug resistance in childhood acute myeloid leukemia. Clin Cancer Res. 2006;12(14):4357-4363.

27. Efferth T, Gillet J-P, Sauerbrey A, et al. Expression profiling of ATPbinding cassette transporters in childhood T-cell acute lymphoblastic leukemia. Mol Cancer Ther. 2006;5(8):1986-1994.

28. Hupfeld T, Chapuy B, Schrader V, et al. Tyrosinekinase inhibition facilitates cooperation of transcription factor SALL4 and ABC transporter A3 towards intrinsic CML cell drug resistance. Br J Haematol. 2013; 161(2):204-213

29. Abedi M, Rahgozar S, Moafi A, et al. Evaluation of the expression profile of MDR1 gene and assessment of its prognostic value in childhood ALL. Sci J Iran Blood Transfus Organ. 2014;10(4): 326-334.
30. Rahgozar S, Moafi A, Abedi M, et al. mRNA expression profile of multidrug-resistant genes in acute lymphoblastic leukemia of children, a prognostic value for ABCA3 and ABCA2. Cancer Biol Ther. 2014; 15(1):35-41.

31. Roy S, Kenny E, Kennedy S, et al. MDR1/P-glycoprotein and MRP-1 mRNA and protein expression in non-small cell lung cancer. Anticancer Res. 2007;27(3A):1325-1330.

32. Ikemura K, Yamamoto M, Miyazaki S, Mizutani H, Iwamoto T, Okuda M. MicroRNA-145 post-transcriptionally regulates the expression and function of P-glycoprotein in intestinal epithelial cells. Mol Pharmacol. 2013;83(2):399-405.

33. Kelley LA, Mezulis S, Yates CM, Wass MN, Sternberg MJ. The Phyre2 web portal for protein modeling, prediction and analysis. Nat Protoc. 2015;10(6):845-858.

34. Paolini A, Baldassarre A, Del Gaudio I, Masotti A. Structural features of the ATP-binding cassette (ABC) transporter ABCA3. Int J Mol Sci. 2015;16(8):19631-19644.

35. Pettersen EF, Goddard TD, Huang CC, et al. UCSF Chimera - a visualization system for exploratory research and analysis. J Comput Chem. 2004;25(13):1605-1612.

36. Lang PT, Brozell SR, Mukherjee S, et al. DOCK 6: combining techniques to model RNA-small molecule complexes. $R N A$. 2009;15(6): 1219-1230.

37. Wolf SJ, Lee CG. ABC Drug Transporters and Their Impact on Drug Disposition/Drug Sensitivity and Resistance. In: Lyubimov A, Sahi J, LeCluyse E, editors. Encyclopedia of Drug Metabolism and Interactions. New York: Wiley; 2012:115-194.

38. Bartholomae S, Gruhn B, Debatin KM, et al. Coexpression of multiple ABC-transporters is strongly associated with treatment response in childhood acute myeloid leukemia. Pediatr Blood Cancer. 2016;63(2): 242-247.

39. Oiso S, Takayama Y, Nakazaki R, et al. Factors involved in the cisplatin resistance of KCP4 human epidermoid carcinoma cells. Oncol Rep. 2014;31(2):719-726.

40. Suvannasankha A, Minderman H, O’Loughlin KL, et al. Breast cancer resistance protein (BCRP/MXR/ABCG2) in acute myeloid leukemia: discordance between expression and function. Leukemia. 2004;18(7): $1252-1257$.
OncoTargets and Therapy

\section{Publish your work in this journal}

OncoTargets and Therapy is an international, peer-reviewed, open access journal focusing on the pathological basis of all cancers, potential targets for therapy and treatment protocols employed to improve the management of cancer patients. The journal also focuses on the impact of management programs and new therapeutic agents and protocols on

\section{Dovepress}

patient perspectives such as quality of life, adherence and satisfaction The manuscript management system is completely online and includes a very quick and fair peer-review system, which is all easy to use. Visit http://www.dovepress.com/testimonials.php to read real quotes from published authors. 